\title{
Strategies for providing effective feedback during preceptorship: Perspectives from an Omani hospital
}

\author{
Gerald A. Matua, Vidya Seshan, Adenike A. Akintola, Anitha N. Thanka \\ College of Nursing, Sultan Qaboos University, Muscat, Sultanate of Oman.
}

Correspondence: Gerald A. Matua. Address: College of Nursing, Sultan Qaboos University, Muscat, Sultanate of Oman. Email: gamandu@squ.edu.om

Received: April 14, 2014

DOI : $10.5430 /$ jnep.v4n10p24
Accepted: July 22, $2014 \quad$ Online Published: August 4, 2014

URL: http://dx.doi.org/10.5430/jnep.v4n10p24

\section{Abstract}

Introduction: Providing effective feedback during preceptorship is essential to advance learning in the clinical area. However in Oman, at present, there is no published data on strategies for giving effective feedback despite the high number of non-Omanis involved in clinical teaching. This study explored the different strategies preceptors at Sultan Qaboos University Hospital use to provide effective feedback.

Methods: A qualitative research design was employed using focus groups, with data collection occurring in November 2012. The focus group discussions were recorded, transcribed and analysed thematically.

Results: Six strategies emerged, among them providing feedback that is regular and timely; clear and focused; emphasising preceptees' performance and progress, as well as respecting preceptee feelings, views and privacy. Other strategies include listening to preceptees and starting with positive remarks during feedback sessions.

Conclusion: Feedback during preceptorship provides preceptors with an excellent opportunity to explain to preceptees where and how they are moving along the continuum of meeting expected goals in relation to attainment of professional knowledge, skills and behaviour, and includes specific suggestions for further improvement. The contextual realities in the clinical environment require preceptors to provide timely, regular, clear and focused feedback that emphasises preceptees' performance, respect their feelings, privacy and opinions. Such feedback techniques when appropriately implemented enable preceptees to improve their performance, by making use of preceptors' constructive criticism, which in turn enables them to rate their clinical practice in a more realistic way, leading them to seek opportunities for further self-improvement.

\section{Key words}

Preceptors, Preceptees, Nursing students, Effective feedback, Clinical teaching, Strategies, Oman

\section{Introduction}

Preceptorship is the systematic process of enabling final year students to function more like qualified professionals ${ }^{[1,2]}$. In health professional education, the practice has become an alternative teaching method to the traditional clinical teaching approach $^{[3]}$. In order to advance learning and inform preceptees of their progress towards attainment of clinical learning objectives, an essential element during preceptorship is providing feedback. Feedback is defined as specific information 
about the comparison between a trainee's observed performance and a standard, given with the intent to improve the trainee's performance ${ }^{[4]}$. Quality feedback can help students rate their clinical practice in a realistic way ${ }^{[5,6]}$ by utilising preceptor's constructive criticisms about their performance, thereby minimizing inaccurate practices ${ }^{[5]}$. When students do not receive appropriate feedback, chances are that some may become over confident and compare themselves with more senior colleagues and evaluate themselves inappropriately. This can lead to falsely increased student self-esteem levels which may have a negative impact on subsequent practice ${ }^{[6,7]}$. Cognisant of these realities in the clinical area, feedback is thus one of the most powerful influences on students' learning, which is essential to enable them, develop critical thinking and lifelong learning skills ${ }^{[3,8]}$. Feedback should be provided on on-going basis throughout preceptees' education to support their cognitive, technical and professional development ${ }^{[3]}$. This continuity is vital since meaningful, timely and effective feedback provides preceptees with learning opportunities to improve their current clinical practices ${ }^{[5,9]}$.

Feedback is considered effective if preceptors' observations and information about preceptees' recent performance promotes positive change and performance ${ }^{[10]}$, and moves them closer to attaining their clinical learning objectives ${ }^{[11]}$, and desired professional socialisation ${ }^{[10,12]}$. Feedback is also effective if it closes the gap between preceptees' current skill and knowledge levels and the desired clinical learning goals ${ }^{[1]}$. It should also provide specific information about desired improvements or corrective changes ${ }^{[10]}$, required in the student's performance, including rationale for any cognitive or performance changes the preceptor recommends ${ }^{[13]}$. Feedback should be related to the students' learning objectives and should be based on students' observed skills and behaviour ${ }^{[13]}$. Effective feedback should address student's progress towards attainment of learning goals and should recommend activities to be undertaken for better progress towards set goals ${ }^{[14]}$.

Feedback is essential for the students' professional growth ${ }^{[16]}$, provides direction and helps to boost their confidence ${ }^{[17]}$, as well as their motivation and self-esteem ${ }^{[3,12]}$. Hence, giving feedback that is supportive, constructive and specific, guides learners in their journey of clinical competence ${ }^{[15]}$. To provide such meaningful feedback, preceptors may question learners to elicit their critical thinking capability and to reflect upon the care preceptees provide to make appropriate judgments about their progress toward attaining their goals ${ }^{[1,18]}$. In terms of timing, feedback should be provided regularly, especially immediately after a critical incident ${ }^{[11,19,20]}$, such as "near-miss", mistake or following an exceptional performance. When a positive relationship exists between a preceptor and a preceptee, providing feedback is relatively straightforward because of the trusting environment ${ }^{[21]}$. However, in the absence of such trust, giving feedback may become a challenging event ${ }^{[21]}$. As a strategy to facilitate feedback process, preceptors are advised to inform preceptees early in the clinical placement on how they intend to assess and provide feedback throughout preceptorship ${ }^{[22]}$. This transparency provides clear-cut information to preceptees, which enables them to understand their right and wrong actions. This in turn acts as platform for correcting their mistakes and enhancing their skills during the placement ${ }^{[9,22]}$.

While the importance of feedback is widely acknowledged, there appears to be inconsistency in the amount, type and timing of feedback received by students in clinical practice ${ }^{[6,23]}$. In the context of Oman, there is scarcity of published data on how this feedback should be organised, including how often it should be given to the students. This lack of current evidenced based information especially in the context of the diverse cultural differences, creates a challenge for clinical teaching and learning, since most preceptors are non-Arabic speaking expatriates and the preceptees are Arabic speaking Omani nationals ${ }^{[24]}$. This knowledge gap requires further inquiry and understanding since feedback problems precipitate preceptor fatigue, frustration and burnout ${ }^{[25]}$, and insufficient support and guidance for preceptees including failure to achieve objectives ${ }^{[2,12]}$.

\section{Objective}

The study sought to explore how nurse preceptors at Sultan Qaboos University Hospital, in Oman provide effective feedback to their assigned preceptees during clinical preceptorship placements. 


\section{Methods}

A qualitative research design using a modified focus group discussion method guided the study. Focus group discussion method was chosen because it is inexpensive, flexible, stimulating, helps with information recall and results in rich data ${ }^{[27,28]}$. Data collection occurred in November 2012 at the College of Nursing, SQU after obtaining research and ethical approval from the College of Nursing Research and Ethics Committee. Prior to data collection, details of the study including purpose and data collection methods were explained to each participant and clarifications were provided. A written consent was obtained from each participant after assuring them of complete confidentiality, anonymity and their right to withdraw from the study anytime without penalty.

Inclusion in the study was limited to preceptors working in emergency, medical, surgical, neonatal and intensive care departments of SQUH who had been assigned this supervisory and mentoring role for final year undergraduate nursing students. Participation was limited to preceptors who had preceptees within the last two years and were fluent in spoken English. In total, 21 preceptors participated, of which $86 \%$ were female and $14 \%$ were male. Most of them had over ten years of clinical experience (76\%) and had worked at SQUH for more than three years (71\%). Just over half (52.5\%) of the preceptors had diploma level education. The remaining $47.5 \%$ were degree holders with an average of four years of preceptorship experience.

The interviewer (AAA) guided an initial focus group discussion of preceptors $(n=5)$ on the strategies they use to provide effective feedback to preceptees against the background of socio-cultural differences that exists between them as expatriate nurses and their Omani preceptees. This small focus group discussion safeguarded group homogeneity and self-disclosure because of the sensitive nature of the topic ${ }^{[28]}$. The group was small enough to allow free discussion and generation of ideas until data redundancy was reached, then the discussion ended ${ }^{[29]}$. After completing the initial focus group discussion, the main findings were discussed in depth within the larger group $(\mathrm{n}=21)$, and suggestions and modifications were made to attain agreement. This member checking procedure validated the initial group findings and aided addition of new data.

The initial and the subsequent focus group discussions were audio recorded using a high-quality tape recorder, in addition to extensive written interview notes (VS, ANT) to augment the audio recordings and to ensure accurate interpretation of data. ${ }^{[28]}$ The interviewers explored the questions: "How do you provide feedback to the students?”, and "What strategy do you use to ensure that the feedback is effective?” Besides these two thematic questions, prompts were utilised to gather in-depth information on preceptors' experiences. The initial focus group discussions $(n=5)$ lasted one hour while the subsequent validation focus group $(\mathrm{n}=21)$ lasted for 20 minutes. Data quality was enhanced by ensuring that all preceptors had shared practical experiences and that they were well qualified to discuss their experiences.

Data analysis commenced after both focus group discussions proceedings were transcribed verbatim and integrated with the field notes. Initially, each team member read and re-read the transcripts, immersing in the data to comprehend the hidden concepts. This process was followed by the second phase of isolating thematic statements using the line-byline-highlighting approach. The thematic statements identified by each researcher were then compared and contrasted and were then modified and validated as key findings of the study. As additional ethical requirement to enhance confidentiality and privacy, all identifying information such as participants' names were removed from the transcripts, instead code numbers were used.

\section{Results}

Six strategies emerged for providing feedback in effective manner during preceptorship. These include providing feedback in a timely and regular manner, in clear and focused way, as well as emphasising performance and progress of preceptees. 
Other strategies included starting with positive feedback, respecting preceptees' feelings and privacy and listening to them, as affirmed in the following verbatim quotes:

Providing timely and regular feedback: Preceptors reported that providing feedback to preceptees about their performance in a timely and regular manner was an effective feedback strategy. Preceptees preferred feedback that was given during or immediately after a learning encounter, regularly and throughout preceptorship period.

"Feedback will be useful when it is given during the procedure, which will avoid further mistakes and harm to the patient.”

In support, another participant adds,

"Feedback should be given after each procedure, which will help the students to develop self-esteem and understand about their mistake...”

Providing clear and focused feedback: Preceptors also noted that when they gave feedback clearly and in a focused manner, preceptees were comfortable with them even though the reviews were negative, as this participant explains:

"Feedback should be given clearly after every shift which will help the student to progress in daily basis"

In terms of focus, preceptors reported that feedback was perceived positively when it concentrated on specific aspects of preceptees' daily or weekly performance of assigned duties.

"Critical elements of the issues should be pointed out”

In affirmation, of the need for focused feedback, another preceptor substantiates that:

"Feedback should have specific areas to point out"

Emphasizing performance and progress: Emphasizing preceptees’ performance of assigned tasks on a continuous basis was noted to be effective feedback strategy. In support, preceptors declared that evaluating and providing feedback continuously, particularly during procedures or shortly after, led to better outcomes:

"Feedback will be more useful if it is given every day, every week and end of each area posting”

Another preceptor corroborates this affirmation by declaring that:

"End of every month feedback will provide overall idea about their performance and progress”

Starting with positive and ending with negative evaluations: In terms of sequence, preceptors noted that their feedback was more accepted and effective when they started off with positive remarks related to preceptees' performance, and then moved to address negative areas that needed improvement, eventually ending with encouraging remarks.

"Reveal positive things first followed by points to improve"

Respecting preceptees' feelings and privacy: While providing feedback, preceptors stated that preceptees were happy when their feelings and privacy were respected when discussing their performance. In fact, preceptees preferred that feedback should be given in private when others are not listening, to avoid embarrassment.

"The environment should be conducive to give feedback when there is no one"

In addition, preceptees preferred that feedback should be given to them when preceptor is calm.

"Preceptor should be calm, collected...while giving feedback to preceptees" 
Listening to preceptees during feedback: The preceptors further observed that listening to preceptees during or shortly after providing feedback about their performance was another vital strategy. This act of paying attention to preceptees' views regarding the feedback proved more productive and resulted in better learning outcomes.

“Listen actively during the feedback and do not ignore students’ opinion or suggestions or problems they faced”

\section{Discussion}

These findings underscore the importance of appropriate feedback as a facilitating factor for effective students learning. A good feedback motivates the preceptee to do better or learn more if it is specific, well timed and focused on behaviour that the learner is able to change ${ }^{[30]}$. Whilst each preceptor had own view on when to provide feedback, there was general agreement that feedback should be timed appropriately, which should be during or shortly after procedures, weekly or monthly basis and at the end of clinical postings. In agreement, studies conducted elsewhere indicate that providing feedback timely, during a procedure and early in a learning situation or promptly after assessing a task facilitates learning because it provides students with opportunity to use the feedback to improve their subsequent performance ${ }^{\text {[11] }}$. Furthermore, providing feedback concurrently as the preceptee performs the assigned task or shortly thereafter, enables preceptors to provide instant corrections and encouragement during the clinical training over procedures ${ }^{[3,32,33]}$. Indeed, providing timely feedback has the advantage of inculcating in the student the correct skills and professional behaviour immediately after an observation. This spotting of mistakes and areas for improvement prevents preceptees from automating incorrect skills, attitudes and behaviour ${ }^{[32,34]}$. In fact, appropriate feedback allows preceptees to gauge their progress towards achieving their learning outcomes, including acquisition of professional skills ${ }^{[5,31]}$.

The strategy of providing clear, specific and focused feedback is consistent with the findings of other studies that affirm that feedback is effective if it is constructive and points to specific ways through which preceptees can improve their learning ${ }^{[10,14]}$. This implies that feedback should 'light the way forward' for the learners by providing vital information on their current performance and guide them to their next steps ${ }^{[10,14,35]}$. The emphasis on specific feedback means that preceptors should include information on how the preceptees are performing their expected tasks. In regard to procedures, specific feedback entails the preceptor explaining what the student did well and what areas need improvement ${ }^{[4,32,36]}$, how the student can improve, as well as other approaches to performing the procedure ${ }^{[32,36]}$. In essence, effective feedback informs preceptees on whether a particular task was performed using a right or wrong approach, enriched with explanations of the preceptors' views. These findings show that clear, focused and specific feedback enables preceptees to achieve their goals. It also shows that feedback can prompt improved performance, especially if preceptees self-evaluate based on feedback information ${ }^{[5,31]}$.

The preceptors also noted that when the feedback emphasized performance and progress each preceptee made in terms of the assigned tasks, outcomes of preceptorship tended to be better. This observation is consistent with the view that feedback that emphasizes performance of specific tasks helps to “close the gap” between preceptees' current level of skill and knowledge and the desired levels ${ }^{[5,32]}$. In order to effectively "close the gap" between the current practices and desired practices, preceptors are expected to provide preceptees both positive and negative feedback ${ }^{[37]}$. In sequence, preceptors noted that to be sensitive to their preceptees and to ensure positive relationships, preceptors should generally start with positive feedback and then tactfully introduce negative areas where the student's performance failed to meet the expected standards. This strategy of starting with positive feedback compares well with the "feedback sandwich" technique, which begins and ends with specific praise (positive message) to build recipient's trust and comfort ${ }^{[35,38]}$, and increases their receptivity to negative comments ${ }^{[35,39]}$. Another advantage of the feedback sandwich is that it also minimises undesirable effects of negative feedback on learners' self-image and increases their motivation and commitment to learn ${ }^{[35,39,40]}$. We also noted that feedback, both positive and negative, is best presented in a manner that enhances their advantages rather than their disadvantages, ensuring that the learner is not discouraged and derailed ${ }^{[5]}$. This implies that positive feedback should be given in a manner that increases preceptees' motivation, performance and self-esteem without causing the 
student to have "inflated ego", associated with counter-productive over-estimation of their clinical performance. In contrast, negative feedback should be given in a manner that allows preceptees to accurately evaluate their knowledge and performance levels and then set out for improvement ${ }^{[4,5]}$.

The strategy of respecting preceptees' feelings and privacy was also another important reality that emerged from the study. The preceptors reiterated the need to provide feedback in friendly manner, while actively portraying oneself as an ally of the preceptee ${ }^{[41,42]}$. Another realisation that emerged from the study was providing feedback in a private and mutually agreed place, away from other health care providers, patients and relatives. Respecting preceptees' feelings and providing feedback away from others protects preceptees from embarrassment, and avoids the possibility of lowering preceptees' intrinsic motivation to learn, making them feel secure ${ }^{[42]}$. This strategy appears to make feedback a less painful experience for the preceptee ${ }^{[40]}$, and potentially led to positive teaching and learning outcomes for both preceptors and preceptees.

Listening to preceptees during the feedback sessions was also argued by the preceptors to portray a sense of caring for preceptees. In order to achieve this, preceptors need to listen to preceptees' opinions, suggestions or explanations for performing the way they did in the assigned tasks. This finding compares well with the assertion that such situations where learners explain their performance of tasks provides specific opportunities to better understand them. Such interactions help deepen the trust between preceptors and preceptees, thus leading to a more vibrant and creative learning relationship ${ }^{[43,44]}$. Likewise, listening to preceptees helps preceptors to know the hindrances they may be experiencing as well as specific issues that need to be incorporated in the teaching learning sessions. In fact, with such background information, preceptors can more easily adjust their subsequent teaching approaches to facilitate better learning for preceptees ${ }^{[43,44]}$.

This study was limited to preceptors from one large university teaching hospital, implying that such findings could be different in less complex settings. This may imply that the views expressed here may not be reflective of preceptors' experiences across the entire country. Also personal biases towards preceptorship could have influenced some views. Despite these limitations, the results offer insight into how feedback can be delivered effectively to preceptees within a clinical environment characterised by Arabic speaking preceptees and non-Arabic speaking preceptors, with the overall aim to improve preceptorship experience for both in future. Another limitation that may have negatively impacted the findings of the present study is the lack of similar studies in Oman and the region, which would have better informed the conclusions drawn during this inquiry.

\section{Conclusion}

Providing feedback in manner that is considered by preceptees to be appropriate and sensitive to them is an important undertaking for all clinical preceptors. This is vital because feedback provides preceptors with an excellent opportunity to explain to their preceptees how they are moving along the continuum of meeting their expected learning goals in terms of professional knowledge, skills and behaviour. Feedback should thus be given in a manner that gives students clear information on where they are in terms of goal attainment as well as specific activities they need to engage in so as to meet their expected professional goals. In view of this, preceptors should therefore provide feedback in a manner that incorporates "best practices" such as providing timely, regular, clear and focused feedback that emphasizes preceptees' actual performance, respects their feelings, privacy and opinions.

We conclude that incorporating appropriate feedback techniques can make preceptorship fulfilling for both preceptors and preceptees. We further share the view that feedback provided in a manner that respects contextual realities of preceptees may help to firmly ground the learner and improve their clinical performance. This improvement in performance comes from their improved ability to rate their clinical practice more realistically, aided by their preceptor's constructive criticisms. We therefore conclude that in the presence of quality feedback, preceptees evaluate themselves better, which allows them to seek opportunities for self-improvement, leading to better outcomes for themselves and their preceptors. 


\section{Acknowledgement}

We thank SQU, College of Nursing for making this study possible. We also thank Dr. Joshua K. Muliira for coordinating Advanced Clinical Nursing course which brought the preceptors together. Finally, we are grateful to the preceptors for sharing their personal views and experiences.

\section{Competing interests}

The authors declare no conflict of interests that inappropriately influenced the study.

\section{References}

[1] Yonge O, Billay D, Myrick F, Luhanga, F. Preceptorship and mentorship: not merely a matter of semantics. Int J Nurs Educ Scholarsh. 2007; 4(1): 1-13. http://dx.doi.org/10.2202/1548-923X.1384

[2] Bourbonnais FF, Kerr, E. Preceptoring a student in the final clinical placement: reflections from nurses in a Canadian Hospital. J Clin Nurs. 2007; 16(8): 1543-1549. http://dx.doi.org/10.1111/j.1365-2702.2006.01828.x

[3] Billay D, Myrick, F. Preceptorship: an integrative review of the literature. Nurse Educ Pract. 2008; 8(4): 258-266. http://dx.doi.org/10.1016/j.nepr.2007.09.005

[4] Van de Ridder JM, Stokking KM, McGaghie WC, Ten Cate, OTJ. What is feedback in clinical education? Med Educ. 2008; 42(2): 189-197. http://dx.doi.org/10.1111/j.1365-2923.2007.02973.x

[5] Plakht Y, Shiyovich A, Nusbaum L, Raizer H. The association of positive and negative feedback with clinical performance, self-evaluation and practice contribution of nursing students. Nurse Educ Today. 2013; 33: 1264-126. http://dx.doi.org/10.1016/j.nedt.2012.07.017

[6] Glover PA. 'Feedback. I listened, reflected and utilized': third year nursing students' perceptions and use of feedback in the clinical setting. Int J Nurs Pract. 2000; 6: 247-252. http://dx.doi.org/10.1046/j.1440-172x.2000.00218.x

[7] Clynes MP, Raftery SE. Feedback: an essential element of student learning in clinical practice. Nurse Educ Pract. 2000; 6: 405-411.

[8] Norcini J. The power of feedback. Med Educ. 2010; 44: 16-7. http://dx.doi.org/10.1111/j.1365-2923.2009.03542.x

[9] University of New South Wales, (UNSW) [Internet]. Australia. Guideline 16: Give students meaningful and timely feedback; [c2013; cited 2014 March 12; 3 screens]. Available from: http://teaching.unsw.edu.au/guideline16.

[10] Hattie J, Timperley H. The Power of Feedback. Rev Educ Res. 2007; 77(1): 81-112. http://dx.doi.org/10.3102/003465430298487

[11] Acher JC. State of the science in health professional education: effective feedback. Med Educ. 2010; 44(1): 101-108. http://dx.doi.org/10.1111/j.1365-2923.2009.03546.x

[12] Duteau J. Making a Difference: The Value of Preceptorship Programs in Nursing Education. J Contin Educ Nurs. 2012 ; $43: 37-43$. http://dx.doi.org/10.3928/00220124-20110615-01

[13] Bott G, Mohinde EA, Lawlor Y. A clinical teaching technique for nurse preceptors: the five minute preceptor. J Prof Nurs. 2011; 27: 35-42. http://dx.doi.org/10.1016/j.profnurs.2010.09.009

[14] Shute VJ. Focus on formative feedback. Rev Educ Res. 2008; 78(1): 153-189. http://dx.doi.org/10.3102/0034654307313795

[15] Osmun WE, Parr J. The occasional teacher. Part 4: feedback and evaluation. Can J Rural Med. 2011; 16(3): 96-7. PMid:21718626

[16] McCarthy M, Higgins A. Moving to an all graduate profession: preparing preceptors for their role. Nurse Educ Today. 2003; 23(2): 89-95. http://dx.doi.org/10.1016/S0260-6917(02)00187-9

[17] Zilembo M, Monterosso L. Towards a conceptual framework for preceptorship in the clinical education of undergraduate nursing students. Contemp Nurse. 2008; 30(1): 89-94. http://dx.doi.org/10.5172/conu.673.30.1.89

[18] Mann K, Van der Vleuten C, Eva K, Armson H, Chesluk B, Dornan T, et al. Tensions in informed self-assessment: how the desire for feedback and reticence to collect and use it can conflict. Academic Medicine. 2011; 86(9): 1120-1127. http://dx.doi.org/10.1097/ACM.0b013e318226abdd

[19] Watling C, Driessen E, Van der Vleuten CP, Vanstone M, Lingard L. Understanding responses to feedback: the potential and limitations of regulatory focus theory. Med Educ. 2012; 46: 593-603. PMid:22626051

[20] Hauer K, Kogan J. Realising the potential value of feedback. Med Educ. 2012; 46: 140-2. http://dx.doi.org/10.1111/j.1365-2923.2011.04180.x

[21] Kidd PS, Parshall MB. Getting the focus and the group: Enhancing analytical rigor in focus group research. Qual Health Res. 2000; 10(3): 293-308. http://dx.doi.org/10.1177/104973200129118453

[22] Chickering AW, Gamson ZF. Seven principles for good practice in undergraduate education. AAHE Bulletin. 1987; 39 (7):3-7. 
[23] Gray MA, Smith LN. The qualities of an effective mentor from the student nurse's perspective: finding from a longitudinal qualitative study. J Adv Nurs. 2000; 32(6): 1542-1549. http://dx.doi.org/10.1046/j.1365-2648.2000.01606.x

[24] Muliira JK, Muliira RS. Teaching culturally appropriate therapeutic touch to nursing students in the Sultanate of Oman: reflections on observations and experiences with Muslim patients. Holist Nurs Pract. 2013; 27(1): 45-48. http://dx.doi.org/10.1097/HNP.0b013e318276fccf

[25] Robinson S, Griffiths P. Preceptorship for newly qualified nurses: impacts, facilitators and constraints-a scoping review. London: National Nursing Research Unit; 2009.

[26] Epstein I, Carlin K. Ethical concerns in the student/preceptor relationship: A need for change. Nurse Educ Today. 2012; 32(8): 897-902. http://dx.doi.org/10.1016/j.nedt.2012.03.009

[27] McLafferty I. Focus group interviews as a data collecting strategy. J Adv Nurs. 2004; 48(2): 187-194. http://dx.doi.org/10.1111/j.1365-2648.2004.03186.x

[28] Streubert HJ, Carpenter DR. Qualitative research in nursing: advancing the humanistic imperative. 5th ed. Philadelphia: Lippincott Press; 2011.

[29] Freeman T. 'Best practice' in focus group research: making sense of different views. J Adv Nurs. 2006; 56(5): $491-497$. http://dx.doi.org/10.1111/j.1365-2648.2006.04043.x

[30] Davis M, McKimm J, Forrest K. How to Assess Doctors and Health Professionals. Chichester, UK: John Wiley \& Sons Ltd; 2013. http://dx.doi.org/10.1002/9781118523469

[31] Curtin University of Technology. Using evaluate to improve student learning: Providing feedback for student learning. Report. Teaching Development Unit, LSN: Curtin University of Technology, Perth, Western Australia; 2013. Available: http://evaluate.curtin.edu.au/local/docs/5providing-feedback-for-student-learning.pdf.

[32] Alken A, Tan E, Luursema JM, Fluit C, van Goor H. Feedback activities of instructors during a trauma surgery course. Am J Surg. 2013; 206(4): 599-604. http://dx.doi.org/10.1016/j.amjsurg.2013.03.011

[33] Roberts NK, Brenner MJ, Williams RG, Kim MJ, Dunnington GL. Capturing the teachable moment: A grounded theory study of verbal teaching interactions in the operating room. Surgery. 2012; 151(5): 643-650. http://dx.doi.org/10.1016/j.surg.2011.12.011

[34] Scheeler MC, Bruno K, Grubb E, Seavey, TL. Generalizing teaching techniques from university to K-12 classrooms: Teaching pre-service teachers to use what they learn. J. Behav Educ. 2009; 18(3): 189-210.http://dx.doi.org/10.1007/s10864-009-9088-3

[35] Parkes J, Abercrombie S, McCarty T. Feedback sandwiches affect perceptions but not performance. Adv Health Sci Educ Theory Pract. 2013; 18(3): 397-407. http://dx.doi.org/10.1007/s10459-012-9377-9

[36] Richardson BK. Feedback. Acad Emerg Med. 2008; 11(12): 1283-12835. http://dx.doi.org/10.1111/j.1553-2712.2004.tb01913.x

[37] Aleassa HM. Performance Appraisal Satisfaction and Counterproductive Behaviours: Direct and Moderating Effects. Int J Business Adm. 2014; 5(1): 76-79.

[38] Dohrenwend A. Serving up the feedback sandwich. Family Practice Management. 2002; 9(10): 43-46.PMid:12469676

[39] Bienstock JL, Katz NT, Cox SM, Hueppchen N, Erickson S, Puscheck EE. To the point: medical education reviews-providing feedback. Am J Obstet Gynecol. 2007; 196(6): 50-513. http://dx.doi.org/10.1016/j.ajog.2006.08.021

[40] Ten Cate, OTJ. Why receiving feedback collides with self-determination. Adv Health Sci Educ Theory Pract. 2013; 18(4): 845-849. http://dx.doi.org/10.1007/s10459-012-9401-0

[41] Clynes M. Providing feedback on clinical performance to student nurses in children’s nursing: challenges facing preceptors. J Children's and Young People’s Nurs. 2008; 2(1): 29-35.

[42] Branch Jr, William, T. Feedback and reflection: teaching methods for clinical settings. Acad Med. 2002; 77: 1185-1188. http://dx.doi.org/10.1097/00001888-200212000-00005

[43] Rodgers CR. Attending to student voice: The impact of descriptive feedback on learning and teaching. Curriculum Inquiry. 2006; 36(2): 209-237. http://dx.doi.org/10.1111/j.1467-873X.2006.00353.x

[44] Oliver M. Listening to the learners: Mentee's perspectives of a mentoring program for first-year science teachers. Teaching Science. 2009; 55(4): 6-11. 